\title{
Changes in the reach of a smoking cessation program in Ontario, Canada, during the COVID-19 pandemic: a cross-sectional study
}

\author{
Nadia Minian PhD, Scott Veldhuizen PhD, Elise Tanzini MA, Stephanie Duench MPH, \\ Wayne K. deRuiter PhD, Megan Barker MA, Laurie Zawertailo PhD, Osnat C. Melamed MD, \\ Peter Selby MBBS
}

\section{Abstract}

Background: Given the harms associated with tobacco use, continuing the provision of smoking cessation treatment during the COVID-19 pandemic is critical. The aim of this study was to examine pandemic-related changes in enrolment, total treatment use and participant characteristics in a large, publicly funded smoking cessation program in Ontario, Canada.

Methods: We conducted a secondary data analysis of patients who enrolled in the program between Jan. 1, 2018, and Dec. 7, 2020. We used descriptive statistics to examine changes in treatment use. To test for differences in sociodemographic and health variables, we used segmented mixed-effects regression with a break point on Mar. 17, 2020, when Ontario declared a state of emergency. We tested 25 variables, using Holm's correction for multiplicity.

Results: We analyzed 60373 enrolments. In the month after the break point, enrolments fell $69 \%$ and total visits fell $42 \%$ relative to previous years. After Mar. 17, 2020, those who enrolled were less likely to report employment in the previous week (absolute expected difference $-12.4 \%, 95 \%$ confidence interval $[\mathrm{Cl}]-15.0 \%$ to $-9.8 \%)$; were more likely to be occasional $(1.3 \%, 95 \% \mathrm{Cl} 0.6 \%$ to $1.9 \%)$ or noncurrent smokers $(1.7 \%, 95 \% \mathrm{Cl} 0.8 \%$ to $2.6 \%)$; were less likely to have set a target quit date $(-4.8 \%, 95 \% \mathrm{Cl}-7.0 \%$ to $-2.6 \%)$; and were more likely to have a physical health $(6.6 \%, 95 \% \mathrm{Cl} 4.0 \%$ to $9.2 \%)$, mental health $(4.6 \%, 95 \% \mathrm{Cl} 1.9 \%$ to $7.2 \%)$ or substance use diagnosis $(3.5 \%, 95 \% \mathrm{Cl} 1.3 \%$ to $5.6 \%)$.

Interpretation: Sharp decreases in new enrolments and subsequent visits to smoking cessation programs were seen when pandemic restrictions were implemented in Ontario, but the characteristics of the people who accessed the programs did not change markedly. Incorporating an equity perspective is essential when new models of care for smoking cessation are developed.

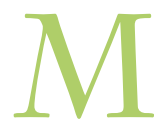
ore than 45000 Canadians die each year from smoking-related illnesses. ${ }^{1}$ Given that at least 1 life can be saved for every 2 people who quit smoking, ${ }^{2}$ smoking cessation remains a public health priority. Evidence-based treatments and clinical practice guidelines recommend that health care providers offer both pharmacotherapy and behavioural interventions ${ }^{3}$ to people who are prepared to make a quit attempt. Supporting people in their attempts to quit smoking during the COVID-19 pandemic is also critical: the latest research indicates that smoking is an important risk factor for the progression of COVID-19, with smokers exhibiting greater symptom severity and higher mortality rates. ${ }^{4,5}$ Although health systems worldwide have been negatively affected by the COVID-19 pandemic and related restrictions, ${ }^{6}$ reports from the Netherlands and Australia have shown increasing receptiveness to smoking cessation during the pandemic, particularly when counselling and pharmacotherapy are free and accessible. ${ }^{7,8}$
Although the COVID-19 pandemic has affected the well-being of all, ${ }^{9}$ it has disproportionately affected populations that experience inequity. ${ }^{10}$ Evidence suggests that problematic substance use and levels of psychological distress have increased during the pandemic. ${ }^{11-14}$ As well, public health measures related to the COVID-19 pandemic have reduced overall health system use and have virtualized health care delivery. ${ }^{15}$ For example, preventive and screening programs for breast, lung and colorectal cancer were halted in Ontario. ${ }^{16}$ These changes may have altered treatment-seeking and referral patterns and created

Competing interests: See the end of the article.

This article has been peer reviewed.

Correspondence to: Peter Selby, peter.selby@ camh.ca CMAJ Open 2021 October 19. DOI:10.9778/cmajo.20210053 
additional barriers for those with limited access to technology or low digital literacy. ${ }^{17-20}$ These issues are of concern for tobacco use, given the associations between tobacco use and other inequities, and the greater need for supports among people who smoke and are of low socioeconomic status. ${ }^{21}$

The purpose of this paper was to evaluate the impact of responses to the COVID-19 pandemic on a smoking cessation program in Ontario, Canada. We specifically examined differences in the total number of participants, total clinical visits and characteristics of participants enrolled before and after the implementation of COVID-19 restrictions.

\section{Methods}

\section{Study design and setting}

In this cross-sectional study, we used enrolment and follow-up data from the Smoking Treatment for Ontario Patients (STOP) Program. STOP is an Ontario smoking cessation program that offers up to 26 weeks of free nicotine replacement therapy and counselling in a 1-year treatment period. Clinics that have implemented the STOP Program include team-based primary care settings and addictions agencies. Although STOP does not directly operate participating clinics, it does provide training and a web-based computerized care pathway, and it supplies long- and short-acting nicotine replacement therapy at no cost. Between 2014 and 2019, over 20000 people enrolled in the STOP Program each year, at approximately 450 clinics across Ontario. STOP largely treats people of lower socioeconomic status: $60 \%$ report an annual total household income of less than $\$ 40000$, and $50 \%$ report having no postsecondary education. ${ }^{22}$

Ontario declared a state of emergency as a result of the COVID-19 pandemic on Mar. 17, 2020. On and shortly after this date, restrictions were implemented that mandated the closure of schools, businesses, indoor public spaces and nonessential workspaces. Similar to other health services that were offered only remotely during this time, many STOP sites transitioned from in-person to virtual care, including enrolment and follow-up visits.

\section{Data source and sample}

Clinics enrol people in the STOP Program using a centralized online portal, which prompts providers to administer a digital baseline questionnaire that includes questions about the person's current tobacco use, health and sociodemographic characteristics. All STOP providers complete a STOP operations training webinar, during which general documentation procedures are covered.

We extracted data from the electronic database of STOP enrolments and clinical visits, and analyzed baseline questionnaires from all participating clinics. To provide a sufficient historical comparison and permit the testing of seasonal effects, we included STOP enrolments and clinical visits from Jan. 1, 2018, to Dec. 7, 2020.

\section{Statistical analysis}

We examined total enrolments and total clinical visits over time. Given the substantial decrease we observed in program enrolments following the declaration of a state of emergency on Mar. 17, 2020, we used this single date in subsequent analyses as the point separating the pre- and post-restriction eras.

To analyze participant characteristics, we included all sociodemographic and health-related variables that are routinely collected at intake. These included previous diagnoses of a number of health conditions, which we combined into 3 binary outcomes indicating the presence of any physical health (heart disease, diabetes, chronic obstructive pulmonary disease, cancer or stroke), mental health (depression, anxiety, bipolar disorder or schizophrenia), or substance use (alcohol or other drugs) diagnoses. If the prevalence of any indicator changed significantly at our break point, we further explored differences in individual diagnoses.

We produced descriptive statistics to characterize participants, and then undertook an exploratory, segmented, mixedeffects regression analysis to test whether participants who enrolled on or after Mar. 17, 2020, differed from those who enrolled before that date in terms of each of the variables listed (Appendix 1, Table S1, available at www.cmajopen.ca/ content/9/4/E957/suppl/DC1, shows definitions of variables). Because participants were nested within clinics, we included a random intercept for clinic in all models.

To account for gradual underlying change, and to examine change in the period on or after Mar. 17, 2020, we modelled time using a 2-part linear spline. However, our primary variable of interest was an indicator variable that was 0 before the break point date and 1 afterward. This variable captured change in the level of each of the variables listed above at the time of the break point. The basic form for each model was $Y_{i j}=\beta_{0}+\beta_{1} T 1_{i j}+\beta_{2} T 2_{i j}+\beta_{2} T_{B r e a k} k_{i j}+u_{i j}+\varepsilon_{i j}$, where $i$ indicated the person and $j$ indicated the site; $T 1$ was the time from Apr. 11, 2016, to Mar. 16, 2020; T2 was the number of days after Mar. 16, 2020; TBreak was an indicator variable that was 0 for dates up to Mar. 16, 2020, and 1 for dates after that; and $u$ was the site-level random intercept.

We also evaluated a set of indicator variables for the month of the year in all initial models. We fitted a separate mixed-effects model (linear for continuous variables, logistic for binary variables and ordinal logistic for ordinal variables) for each participant characteristic. We tested 25 such variables and adjusted for multiplicity using the step-down method of Holm, with an initial $p$ value threshold of $0.002 .^{23,24}$

Our modelling approach required that any gradual change over time before and after the break point be approximately linear. Because the very large sample size would make small deviations statistically significant, we evaluated the linearity of change by visually examining monthly means. We excluded e-cigarette use from the previous month, which had a complex pattern of change that was unrelated to our break point. We were also unable to fit a model for rural residence, which was too strongly associated with the clinic attended. Changes in participant characteristics could also have been associated with seasonal variation. To address this possibility, we fitted each model with 
Table 1 (part 1 of 2): Descriptive statistics for all baseline variables by date of admission

\begin{tabular}{|c|c|c|c|c|}
\hline \multirow[b]{2}{*}{ Variable } & \multicolumn{2}{|c|}{ Jan. 1, 2017, to Mar. 16, 2020} & \multicolumn{2}{|c|}{ Mar. 17,2020 , to Dec. 7,2020} \\
\hline & $\begin{array}{c}\text { Responses } \\
n=51275 \\
\% \text { or mean } \pm \text { SD }\end{array}$ & $\begin{array}{c}\text { Missing, } \\
\text { no. (\%) }\end{array}$ & $\begin{array}{c}\text { Responses } \\
n=9098 \\
\% \text { or mean } \pm \text { SD }\end{array}$ & $\begin{array}{l}\text { Missing, } \\
\text { no. (\%) }\end{array}$ \\
\hline Sex/gender* & & $86(<1)$ & & $5(<1)$ \\
\hline Male & 50 & & 48 & \\
\hline Female & 50 & & 52 & \\
\hline Other & 0.2 & & 0.2 & \\
\hline Age, yr & $51.3 \pm 14.0$ & $48(<1)$ & $51.7 \pm 14.2$ & $19(<1)$ \\
\hline Age began smoking daily, yr & $17.0 \pm 5.4$ & $4051(8)$ & $17.1 \pm 5.4$ & $683(8)$ \\
\hline Smoking status at baseline & & $140(<1)$ & & $27(<1)$ \\
\hline Daily & 93 & & 94 & \\
\hline Occasionally & 3 & & 3 & \\
\hline Not at all & 4 & & 3 & \\
\hline No. cigarettes per day & $18.4 \pm 12.1$ & $258(1)$ & $18.7 \pm 11.9$ & $36(<1)$ \\
\hline Time to first cigarette after waking, min & & $2575(5)$ & & $422(5)$ \\
\hline Within 5 & 40 & & 40 & \\
\hline $6-30$ & 38 & & 38 & \\
\hline $31-60$ & 12 & & 11 & \\
\hline More than 60 & 10 & & 10 & \\
\hline Previous lifetime quit attempts & & $1174(2)$ & & $221(2)$ \\
\hline None & 9 & & 8 & \\
\hline 1 to 5 times & 60 & & 60 & \\
\hline 6 to 10 times & 16 & & 17 & \\
\hline 11 or more times & 15 & & 16 & \\
\hline Has quit date & 52 & $0(<1)$ & 46 & $0(<1)$ \\
\hline Importance of quittingt & $9 \pm 1.4$ & $490(1)$ & $9.1 \pm 1.4$ & $130(1)$ \\
\hline Confidence in ability to quit $†$ & $7.4 \pm 2.1$ & $624(1)$ & $7.4(2.0)$ & $157(2)$ \\
\hline Physical health diagnosisł & 44 & $5865(11)$ & 48 & $1597(18)$ \\
\hline Mental health diagnosis§ & 54 & $5454(11)$ & 59 & $1483(16)$ \\
\hline Substance-related diagnosis & 21 & $3431(7)$ & 22 & $1247(14)$ \\
\hline First Nations, Métis or Inuit & 7 & $2884(6)$ & 7 & $1280(14)$ \\
\hline Education & & $3922(8)$ & & $1690(19)$ \\
\hline$<$ Secondary & 25 & & 25 & \\
\hline Secondary & 26 & & 27 & \\
\hline Some postsecondary & 18 & & 16 & \\
\hline Postsecondary & 31 & & 32 & \\
\hline Household income, ${ }^{* \star} \$$ & & $18549(36)$ & & $4415(49)$ \\
\hline$\leq 20000$ & 41 & & 43 & \\
\hline $20000-40000$ & 21 & & 22 & \\
\hline$>40000$ & 38 & & 35 & \\
\hline Not working in past week†† & 54 & $2141(6)$ & 61 & $974(14)$ \\
\hline Ontario Drug Benefit program & 46 & $4044(8)$ & 46 & $1364(15)$ \\
\hline Body mass index & $27.7 \pm 6.4$ & $5361(10)$ & $27.9 \pm 6.6$ & $1055(12)$ \\
\hline
\end{tabular}




\begin{tabular}{|c|c|c|c|c|}
\hline \multirow[b]{2}{*}{ Variable } & \multicolumn{2}{|c|}{ Jan. 1, 2017, to Mar. 16, 2020} & \multicolumn{2}{|c|}{ Mar. 17,2020 , to Dec. 7, 2020} \\
\hline & $\begin{array}{c}\text { Responses } \\
n=51275 \\
\% \text { or mean } \pm \text { SD }\end{array}$ & $\begin{array}{c}\text { Missing, } \\
\text { no. (\%) }\end{array}$ & $\begin{array}{c}\text { Responses } \\
n=9098 \\
\% \text { or mean } \pm \text { SD }\end{array}$ & $\begin{array}{l}\text { Missing, } \\
\text { no. (\%) }\end{array}$ \\
\hline AUDIT-C scoreł‡ & $2.8 \pm 3.1$ & $2787(5)$ & $2.7 \pm 3.1$ & $1165(13)$ \\
\hline PHQ-2 score§§ & $1.2 \pm 1.7$ & $3681(7)$ & $1.3 \pm 1.7$ & $1347(15)$ \\
\hline 30-day opioid use & 16 & $2125(4)$ & 16 & $1044(11)$ \\
\hline 30-day cannabis use & 32 & $2169(4)$ & 35 & $1038(11)$ \\
\hline 30-day mental health service use & 26 & $3072(6)$ & 26 & $1173(13)$ \\
\hline Caffeine servings per day & & $1737(3)$ & & $984(11)$ \\
\hline None & 6 & & 7 & \\
\hline 1 or 2 & 37 & & 39 & \\
\hline 3 to 5 & 40 & & 38 & \\
\hline More than 5 & 17 & & 17 & \\
\hline \multicolumn{5}{|c|}{ 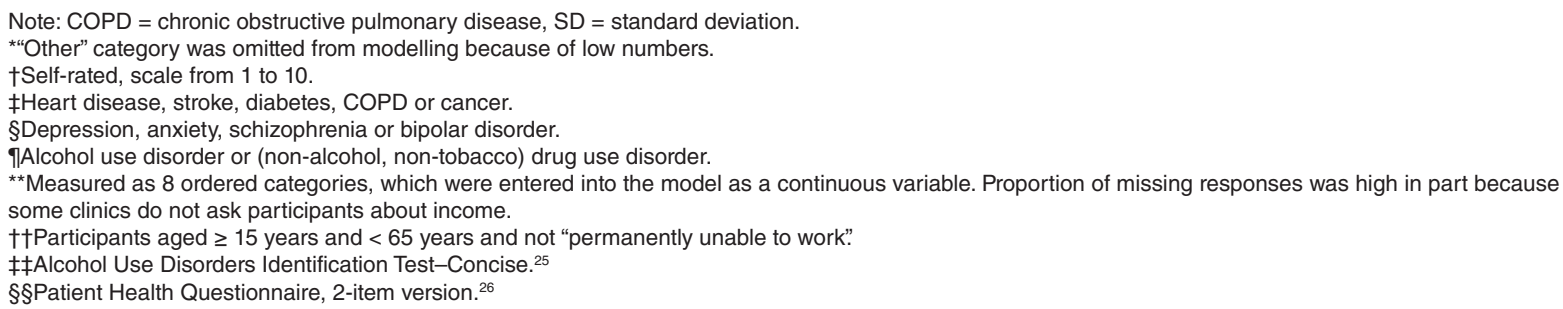 } \\
\hline
\end{tabular}

added month-of-year indicator variables, and then we tested the joint significance of these indicators. When these tests produced a $p$ value of less than 0.05 , we included month-of-year indicators in the final model. Because the amount of missing data for most variables was relatively small and variables were analyzed separately, we omitted cases with missing values from the analysis.

The STOP Program permits people to re-enrol after their initial 1-year treatment period has expired. To evaluate the effect of repeated enrolments, we conducted a sensitivity analysis using probabilistic deduplication to identify repeat enrolments, randomly selecting 1 enrolment per individual and rerunning the main analysis.

\section{Ethics approval}

The STOP Program is funded by the Ontario Ministry of Health, and its procedures were approved by the Research Ethics Board at the Centre for Addiction and Mental Health (protocol numbers 058-2011 and 154-2012). Participants provided written informed consent at baseline for the use of their data for research and publications.

\section{Results}

During the study period, 61291 enrolments were initiated. We removed $595(1.0 \%)$ because consent for participation had not been received and $323(0.5 \%)$ because the enrolment had not otherwise been completed. This left an analysis sample of 60373 enrolments and 248996 clinical visits, of which 9098 (15\%) and 44804 (18\%), respectively, took place on or after Mar. 17, 2020. Descriptive statistics are shown in Table 1, and changes in enrolments and clinical visits over time are shown in Figures 1 and 2.

In the month following Mar. 17, 2020, enrolments were $69 \%$ lower and visits were $42 \%$ lower than the average of the same period in the 2 previous years. Enrolments began a gradual recovery in April 2020, but visits continued to decline slightly into that summer and increased only in September 2020. After adjustment for multiplicity, we found significant changes at this break point for 6 participant-level variables: people enrolling after this time were more likely to have physical health, mental health and substance use diagnoses; less likely to have worked in the previous week; less likely to have set a specific date to quit smoking; and more likely to be nonsmokers or occasional smokers (Table 2).

Figure 3 illustrates the results of the model. After the initial change, employment in the previous week, smoking status and prevalence of physical health diagnoses showed signs of returning to their earlier means. Effects for variables that did not meet our criterion for significance were small, with absolute logits for binary or ordinal variables below 0.15 (odds ratio 1.16) and standardized effect sizes for continuous variables below 0.06 . For specific health conditions, we found significant $(p<0.05)$ prevalence increases for chronic obstructive pulmonary disease, anxiety, diabetes, cancer, bipolar disorder, heart disease and drug use disorders after Mar. 17, 2020. Appendix 2, Supplementary Table S2, available at www.cmajopen.ca/content/9/4/E957/suppl/DC1, presents complete model results. 


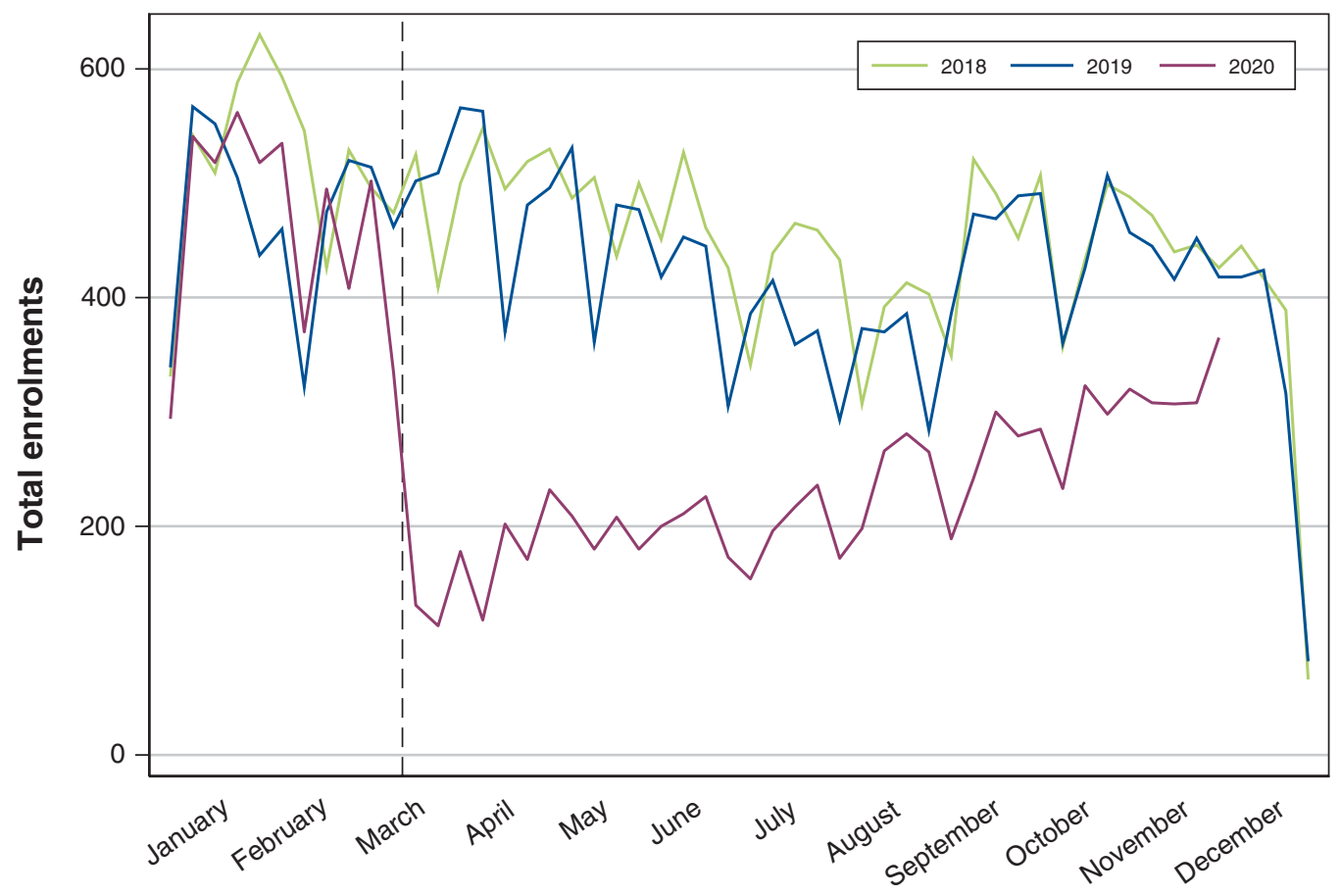

Figure 1: Total new Smoking Treatment for Ontario Patients (STOP) enrolments by week of year.

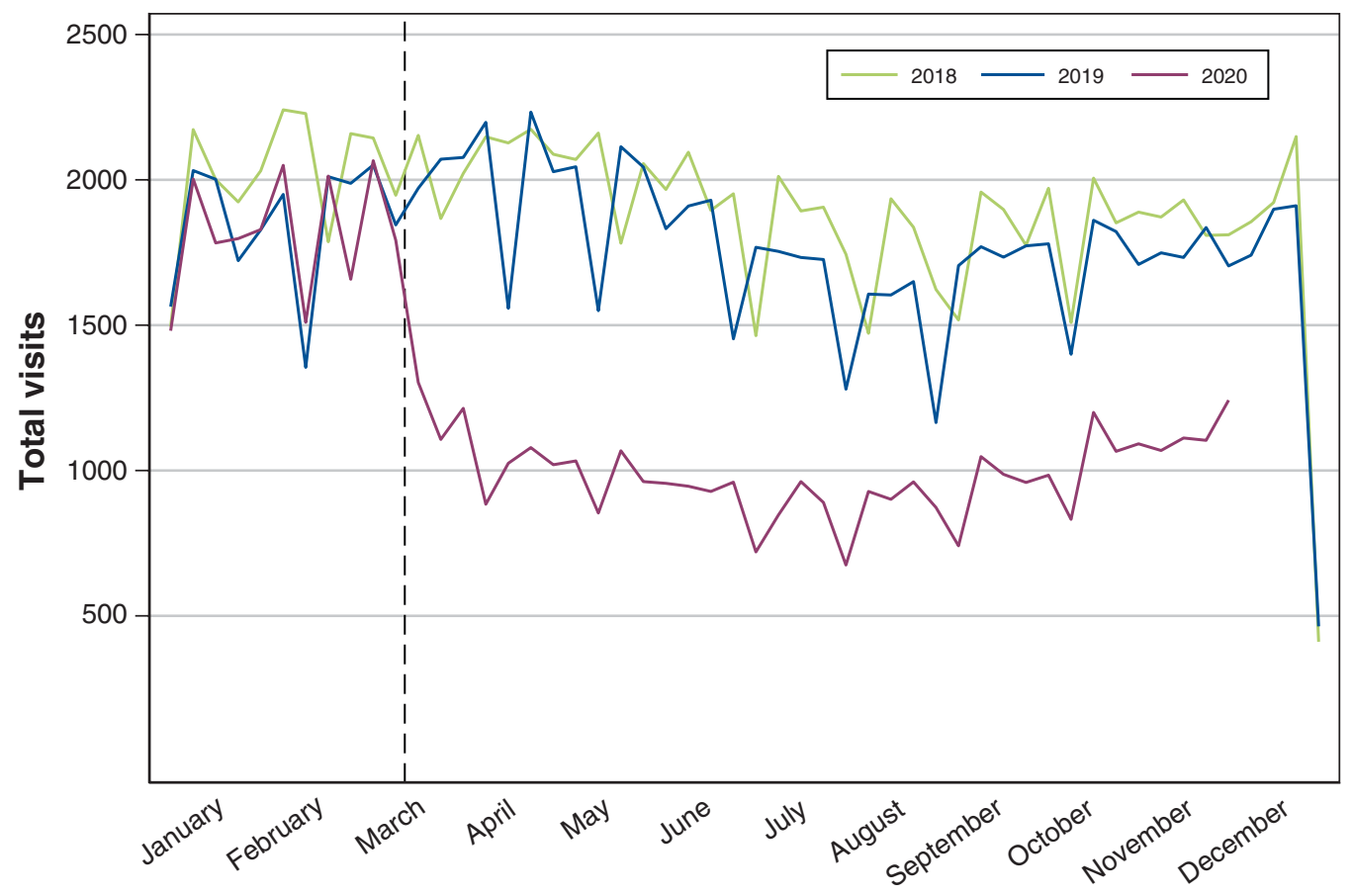

Figure 2: Total Smoking Treatment for Ontario Patients (STOP) visits by week of year. 


\begin{tabular}{|c|c|c|c|c|c|c|}
\hline Variable & $\begin{array}{l}\text { Pre-break } \\
\text { slope }\end{array}$ & $\begin{array}{l}\text { Post-break } \\
\text { slope }\end{array}$ & $\begin{array}{l}\text { Level } \\
\text { change }\end{array}$ & $\begin{array}{l}\text { Level } \\
\text { change } \\
p \text { value }\end{array}$ & $\begin{array}{l}\text { Slope } \\
\text { change } \\
p \text { value }\end{array}$ & $\begin{array}{c}\text { Absolute expected } \\
\text { difference } \\
\%(95 \% \mathrm{Cl}) \dagger\end{array}$ \\
\hline Physical health diagnosis & $\begin{array}{c}1.002 \\
\text { (0.999 to } 1.004)\end{array}$ & $\begin{array}{c}0.972 \\
(0.954 \text { to } 0.991)\end{array}$ & $\begin{array}{c}1.33 \\
(1.19 \text { to } 1.49)\end{array}$ & $<0.001$ & 0.002 & $\begin{array}{c}6.6 \\
(4.0 \text { to } 9.2)\end{array}$ \\
\hline Has quit date & $\begin{array}{c}1.000 \\
\text { (0.997 to } 1.002)\end{array}$ & $\begin{array}{c}1.003 \\
(0.985 \text { to } 1.021)\end{array}$ & $\begin{array}{c}0.80 \\
(0.72 \text { to } 0.88) \\
\end{array}$ & $<0.001$ & 0.7 & $\begin{array}{c}-4.8 \\
(-7.0 \text { to }-2.6)\end{array}$ \\
\hline Not working & $\begin{array}{c}1.000 \\
(0.997 \text { to } 1.003)\end{array}$ & $\begin{array}{c}0.946 \\
(0.925 \text { to } 0.967)\end{array}$ & $\begin{array}{c}1.83 \\
(1.60 \text { to } 2.09)\end{array}$ & $<0.001$ & $<0.001$ & $\begin{array}{c}12.4 \\
\text { (9.8 to } 15.0)\end{array}$ \\
\hline Smoking status $\ddagger$ & $\begin{array}{c}0.988 \\
(0.984 \text { to } 0.993)\end{array}$ & $\begin{array}{c}0.937 \\
\text { (0.904 to } 0.972)\end{array}$ & $\begin{array}{c}1.56 \\
\text { (1.27 to } 1.91)\end{array}$ & $<0.001$ & 0.004 & \\
\hline Occasional smoker & & & & & & $\begin{array}{c}1.3 \\
(0.6 \text { to } 1.9)\end{array}$ \\
\hline Current nonsmoker & & & & & & $\begin{array}{c}1.7 \\
(0.8 \text { to } 2.6)\end{array}$ \\
\hline Mental health diagnosis & $\begin{array}{c}1.001 \\
\text { (0.998 to } 1.003)\end{array}$ & $\begin{array}{c}0.998 \\
(0.977 \text { to } 1.019)\end{array}$ & $\begin{array}{c}1.23 \\
\text { (1.09 to } 1.39)\end{array}$ & 0.001 & 0.8 & $\begin{array}{c}4.6 \\
\text { (1.9 to } 7.2)\end{array}$ \\
\hline Substance use diagnosis§ & $\begin{array}{c}1.003 \\
\text { (0.999 to } 1.006)\end{array}$ & $\begin{array}{c}0.972 \\
\text { (0.949 to } 0.997)\end{array}$ & $\begin{array}{c}1.27 \\
\text { (1.10 to } 1.47)\end{array}$ & 0.001 & 0.02 & $\begin{array}{c}3.5 \\
\text { (1.3 to } 5.6)\end{array}$ \\
\hline \multicolumn{7}{|l|}{ Specific diagnoses } \\
\hline COPD & $\begin{array}{c}1.001 \\
\text { (0.998 to } 1.004)\end{array}$ & $\begin{array}{c}0.969 \\
(0.95 \text { to } 0.989)\end{array}$ & $\begin{array}{c}1.38 \\
(1.23 \text { to } 1.56)\end{array}$ & $<0.001$ & 0.002 & $\begin{array}{c}6.2 \\
\text { (3.9 to } 8.5)\end{array}$ \\
\hline Anxiety & $\begin{array}{c}1.002 \\
\text { (0.999 to } 1.004)\end{array}$ & $\begin{array}{c}0.992 \\
(0.974 \text { to } 1.01)\end{array}$ & $\begin{array}{c}1.20 \\
\text { (1.07 to } 1.33)\end{array}$ & 0.001 & 0.3 & $\begin{array}{c}4.1 \\
\text { (1.7 to } 6.6)\end{array}$ \\
\hline Diabetes & $\begin{array}{c}1.000 \\
\text { (0.997 to } 1.004)\end{array}$ & $\begin{array}{c}0.978 \\
(0.955 \text { to } 1.002)\end{array}$ & $\begin{array}{c}1.19 \\
(1.03 \text { to } 1.37)\end{array}$ & 0.02 & 0.07 & $\begin{array}{c}2.2 \\
(0.3 \text { to } 4.2)\end{array}$ \\
\hline Cancer & $\begin{array}{c}1.004 \\
\text { (0.999 to } 1.008)\end{array}$ & $\begin{array}{c}0.970 \\
(0.941 \text { to } 0.999)\end{array}$ & $\begin{array}{c}1.26 \\
\text { (1.06 to } 1.51)\end{array}$ & 0.01 & 0.03 & $\begin{array}{c}1.9 \\
(0.3 \text { to } 3.5)\end{array}$ \\
\hline Bipolar disorder & $\begin{array}{c}0.998 \\
\text { (0.993 to } 1.002)\end{array}$ & $\begin{array}{c}0.991 \\
\text { (0.959 to } 1.023)\end{array}$ & $\begin{array}{c}1.25 \\
\text { (1.03 to } 1.51)\end{array}$ & 0.02 & 0.7 & $\begin{array}{c}1.6 \\
(0.1 \text { to } 3.1)\end{array}$ \\
\hline Drug use disorderף & $\begin{array}{c}1.002 \\
(0.999 \text { to } 1.006)\end{array}$ & $\begin{array}{c}0.961 \\
\text { (0.934 to } 0.989)\end{array}$ & $\begin{array}{c}1.21 \\
\text { (1.02 to } 1.43)\end{array}$ & 0.02 & 0.004 & $\begin{array}{c}2.2 \\
(0.2 \text { to } 4.2)\end{array}$ \\
\hline Heart disease & $\begin{array}{c}1.002 \\
\text { (0.999 to } 1.006)\end{array}$ & $\begin{array}{c}0.995 \\
(0.97 \text { to } 1.021)\end{array}$ & $\begin{array}{c}1.17 \\
(1.00 \text { to } 1.36)\end{array}$ & 0.04 & 0.6 & $\begin{array}{c}1.7 \\
(0.0 \text { to } 3.4)\end{array}$ \\
\hline \multicolumn{7}{|c|}{$\begin{array}{l}\text { Note: } \mathrm{Cl}=\text { confidence interval, } \mathrm{COPD}=\text { chronic obstructive pulmonary disease, } \mathrm{OR}=\text { odds ratio. } \\
{ }^{*} \text { Fixed effects from mixed-effects logistic models. Slope values show change per } 30 \text {-day interval. Slope change } p \text { values are from post-estimation tests of differences } \\
\text { in slopes before and after the state of emergency declaration. Specific diagnoses are included in the broader diagnosis categories, and are shown for all conditions } \\
\text { with } p<0.05 \text {. For other variables, Holm adjustment for multiplicity was applied. } \\
\text { †Difference between predicted probabilities immediately before and after the state of emergency declaration. } \\
\text { łBaseline smoking status: daily smoker, occasional smoker, nonsmoker. As an ordinal outcome, expected differences are shown for the occasional and nonsmoker } \\
\text { categories. } \\
\text { \$Alcohol or non-tobacco drug use disorder. } \\
\text { शNon-tobacco, non-alcohol drug use disorder. }\end{array}$} \\
\hline
\end{tabular}

\section{Sensitivity analysis}

Deduplication indicated that the 60373 enrolments represented 52874 individuals; 7499 (12.4\%) people had enrolled more than once. In our sensitivity analysis, which included only 1 enrolment per participant, the coefficient of the break point term for a physical health diagnosis was reduced by $24 \%$. However, this effect still met our criterion for significance. Coefficients for our other variables changed by $7 \%$ or less. No other variables met our criteria for significance that had not done so in the primary analysis.

\section{Interpretation}

When public health restrictions were implemented in Ontario as a result of the COVID-19 pandemic, a province-wide smoking cessation program experienced sharp decreases in new enrolments. Visits were less affected at first because of ongoing care for existing enrolments, but they took much longer to begin recovering. As participants completed treatment, visits became a reflection of enrolments over the immediately preceding period. With minor exceptions, the characteristics of people who enrolled in the STOP Program were 


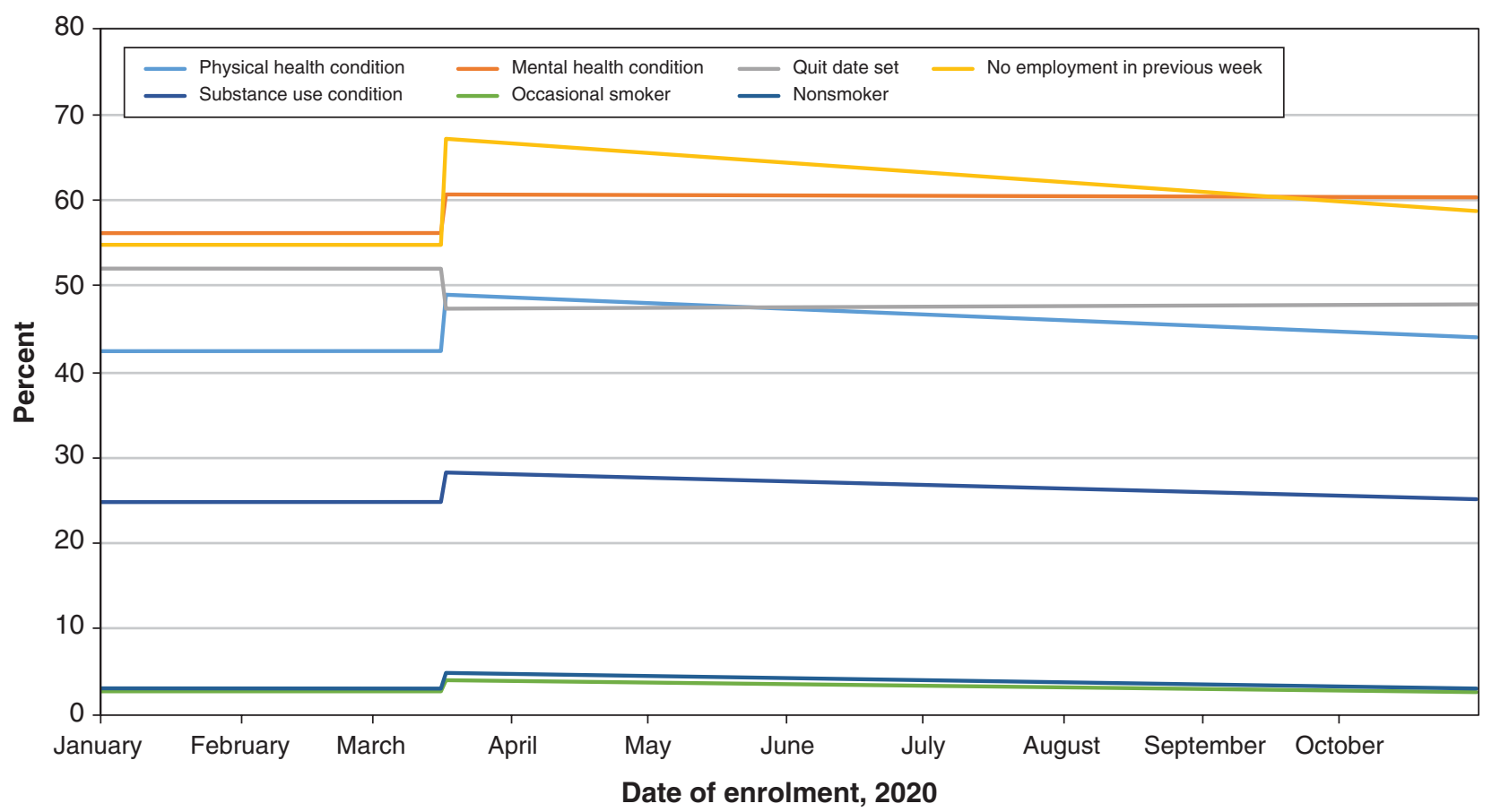

Figure 3: Marginal predictions from models of change over time for participant characteristics with significant differences before and after the state of emergency was declared. Note: the figure shows the predicted probability of each characteristic by date of enrolment. Changes in March 2020 reflect shifts associated with the onset of the COVID-19 pandemic.

quite similar before and after implementation of the state of emergency. The change in enrolments in the STOP Program and their subsequent slow recovery might be attributable to the fact that many primary care sites were partially closed for nonurgent matters at the beginning of the lockdown, consistent with reductions in other in-person health care services in Ontario and beyond..$^{15,27,28}$

The changes we observed for STOP participants' employment in the previous week may have reflected layoffs related to COVID-19. ${ }^{29}$ The increased number of STOP participants who reported physical health, mental health and substance use diagnoses might have reflected a referral effect, because about $70 \%$ of participants are referred by other health care providers. Although the use of nonurgent health care services fell sharply early in the pandemic, ${ }^{15}$ those who required continuous management for pre-existing health conditions were likely to have continued accessing care after Mar. 17, 2020. As a result, they would have had greater opportunities for referral.

There is also evidence that the prevalence or severity of some mental health and substance-related problems increased during the pandemic, ${ }^{30,31}$ so the changes we observed for these conditions may also reflect an overall increase in the population as a whole. The proportion of patients who were nondaily smokers rose at the beginning of the pandemic, but the absolute change was very small and the effect was transient. Finally, our finding that participants were less likely to have a quit date is concerning, because evidence suggests that a quit date is associated with a greater likelihood of making a successful quit attempt. ${ }^{32}$ It is possible that this change was related to uncertainty around the provision of treatment during a pandemic. It could also have been related to our finding that participants were more likely to report a mental health and substance use condition, which has been negatively associated with having a quit date. ${ }^{33}$

COVID-19 disproportionately affects those who are already adversely affected by social determinants of health. ${ }^{34}$ In this study, we demonstrated that although the STOP Program's reach was negatively affected by the COVID-19 pandemic, services were provided to participants who experienced inequities such as unemployment or comorbid physical or mental health conditions. The digital divide in Canada, which has made it increasingly challenging for populations that face inequities to stay connected (and for the health sector to provide support during COVID-1920,35) did not seem to prevent participants of low socioeconomic status from enrolling in the STOP Program. However, given STOP's engagement with those who report inequities, the overall reduction in program capacity will have affected these individuals.

Future research could examine the perceived smoking cessation supports required by participants who enrolled after Mar. 17, 2020, because this could offer direction on key features that should be included in a smoking cessation program 
operating at a time of crisis. It will also be important to examine whether retention of participants and treatment outcomes changed during the pandemic. Finally, understanding the different mechanisms and components that allowed the STOP Program to continue reaching people who were experiencing inequities will be useful for guiding future adaptations and support the generalizability of research findings.

The COVID-19 pandemic created a critical need to develop new ways of delivering care, and many of these changes have followed the principles outlined in "the inverse care law," which postulates that the availability of medical or social care tends to vary inversely with the need of the population served. ${ }^{36}$ To help achieve Canada's commitment of 5\% smoking prevalence by $2035,{ }^{37}$ it is essential to invest in helping people quit smoking, especially those who experience inequities, even when budget constraints are likely as a result of COVID-19 and its aftermath.

\section{Limitations}

Our study included a large sample size, a broad range of variables and a study period that permitted meaningful examination of changes related to the COVID-19 pandemic. However, variables included in the present study were limited to available data, which did not allow us to explore whether specific racial and ethnic populations (apart from First Nations, Inuit and Métis) who participated in the STOP Program were disproportionately affected by pandemic-related changes.

Most variables had some missing values, and these were somewhat more common after the pandemic began. Although this may have been because completing surveys remotely was more difficult, changes in the mechanisms that produced missing responses are a possible source of bias. We lacked information about changes in demand for smoking cessation services during this period, and thus were unable to account for it. Finally, we were unable to fit a model for rural residence, because this variable was strongly associated with the clinic attended.

\section{Conclusion}

Our study shows that changes in the STOP Program did not negatively affect those who needed care the most; few groups were specifically affected (in terms of access to smoking cessation) by changes related to the pandemic. However, the large drop in program enrolments shows that treatment availability and use were sharply reduced early in the pandemic. When developing new models of care delivery for smoking cessation, we must ensure that people who are facing greater systemic barriers can access and benefit from these supports. This may involve creating innovative and flexible approaches to accessing evidence-based smoking cessation supports (e.g., remotely delivered pharmacotherapy and psychosocial supports) tailored to the needs of people who face inequities.

\section{References}

1. Dobrescu A, Bhandari A, Sutherland G, et al. The costs of tobacco use in Canada, 2012. Ottawa: Conference Board of Canada; 2017.

2. West R. The clinical significance of "small" effects of smoking cessation treatments. Addiction 2007;102:506-9.
3. CAN-ADAPTT practice-informed guidelines. Toronto: Canadian Action Network for the Advancement, Dissemination and Adoption of Practice-informed Tobacco Treatment, Centre for Addiction and Mental Health; 2011.

4. Alqahtani JS, Oyelade T, Aldhahir AM, et al. Prevalence, severity and mortality associated with COPD and smoking in patients with COVID-19: a rapid systematic review and meta-analysis. PLoS One 2020;15:e0233147.

5. Gülsen A, Yigitbas BA, Uslu B, et al. The effect of smoking on COVID-19 symptom severity: systematic review and meta-analysis. Pulm Med 2020;2020:7590207.

6. Maintaining essential bealth services during the COVID-19 outbreak 2020. Geneva: World Health Organization; 2020. Available: www.who.int/emergencies /diseases/novel-coronavirus-2019/related-health-issues (accessed 2021 Jan. 21).

7. Pettigrew S, Jun M, Roberts I, et al. Preferences for tobacco cessation information and support during COVID-19.7 Addict Med 2020;14:e362-5.

8. Elling JM, Crutzen R, Talhout R, et al. Tobacco smoking and smoking cessation in times of COVID-19. Tob Prev Cessat 2020;6:39.

9. From risk to resilience: an equity approach to COVID-19. Ottawa: Public Health Agency of Canada; 2020. Available: www.canada.ca/en/public-health/corporate/ publications/chief-public-health-officer-reports-state-public-health-canada/from -risk-resilience-equity-approach-covid-19.html (accessed 2021 Jan. 20).

10. Glover RE, van Schalkwyk MCI, Akl EA, et al. A framework for identifying and mitigating the equity harms of COVID-19 policy interventions. 7 Clin Epidemiol 2020;128:35-48.

11. Yach D. Tobacco use patterns in five countries during the COVID-19 lockdown. Nicotine Tob Res 2020;22:1671-2.

12. Rehm J, Kilian C, Ferreira-Borges C, et al. Alcohol use in times of the COVID 19: implications for monitoring and policy. Drug Alcohol Rev 2020;39:301-4.

13. Lima CKT, de Medeiros Carvalho PM, de Araújo Araruna Silva Lima I, et al. The emotional impact of coronavirus 2019-nCoV (new coronavirus disease). Psychiatry Res 2020;287:112915.

14. Xiang Y'T, Yang Y, Li W, et al. Timely mental health care for the 2019 novel coronavirus outbreak is urgently needed. Lancet Psychiatry 2020;7:228-9.

15. How COVID-19 affected physician services. Ottawa: Canadian Institute for Health Information; 2020. Available: www.cihi.ca/en/covid-19-resources/ impact-of-covid-19-on-canadas-health-care-systems/how-covid-19-affected -physician-services (accessed 2021 Jan. 22).

16. Cancer screening during COVID-19: message for the public. Toronto: Cancer Care Ontario. Available: www.cancercareontario.ca/en/get-checked-cancer/ screening-during-covid-19 (accessed 2021 Feb. 12).

17. Béland L-P, Brodeur A, Mikola D, et al. The short-term economic consequences of COVID-19: occupation tasks and mental health in Canada. IZA Discussion Paper No. 13254. Bonn (Germany): Institute for the Study of Labor (IZA); 2020. Available: https://ssrn.com/abstract=3602430 (accessed 2021 Jan. 21).

18. Blumenthal D, Fowler EJ, Abrams M, et al. COVID-19: implications for the health care system. N Engl 7 Med 2020;383:1483-8.

19. Beaunoyer E, Dupéré S, Guitton MJ. COVID-19 and digital inequalities: reciprocal impacts and mitigation strategies. Comput Human Behav 2020;111:106424.

20. Lam K, Lu AD, Shi Y, et al. Assessing telemedicine unreadiness among older adults in the United States during the COVID-19 pandemic. 7 AMA Intern Med 2020;180:1389-91.

21. Corsi DJ, Boyle MH, Lear SA, et al. Trends in smoking in Canada from 1950 to 2011: progression of the tobacco epidemic according to socioeconomic status and geography. Cancer Causes Control 2014;25:45-57.

22. Baliunas D, Zawertailo L, Voci S, et al. Variability in patient sociodemographics, clinical characteristics, and healthcare service utilization among 107,302 treatment seeking smokers in Ontario: a cross-sectional comparison. PLoS One 2020;15:e235709.

23. Holm S. A simple sequentially rejective multiple test procedure. Scand 7 Stat 1979;6:65-70.

24. Streiner DL. Best (but oft-forgotten) practices: the multiple problems of multiplicity-whether and how to correct for many statistical tests. Am 7 Clin Nutr 2015;102:721-8.

25. Bush K, Kivlahan DR, McDonell MB, et al. The AUDIT alcohol consumption questions (AUDIT-C): an effective brief screening test for problem drinking. Ambulatory Care Quality Improvement Project (ACQUIP). Alcohol Use Disorders Identification Test. Arch Intern Med 1998;158:1789-95.

26. Kroenke K, Spitzer RL. The PHQ-9: a new depression diagnostic and severity measure. Psychiatr Ann 2002;32:509-15.

27. Alexander GC, Tajanlangit M, Heyward J, et al. Use and content of primary care office-based vs telemedicine care visits during the COVID-19 pandemic in the US. FAMA Netw Open 2020;3:e2021476.

28. Glazier RH, Green ME, Wu FC, et al. Shifts in office and virtual primary care during the early COVID-19 pandemic in Ontario, Canada. CMAf 2021;193:E200-10.

29. Ontario employment reports. Fanuary to March, 2020. Toronto: Economic Development, Job Creation and Trade Communications Branch; 2020. Available: www. ontario.ca/document/ontario-employment-reports/january-march-2020\#: :text= Ontario's\%20labour\%20market\%20overview\&text=Year\%2Dover\%2Dyear\%2C \%20Ontario's,the\%20Canadian\%20rate\%20of\%206.7\%25 (accessed 2021 Feb. 1).

30. McPhee MD, Keough MT, Rundle S, et al. Depression, environmental reward, coping motives and alcohol consumption during the COVID-19 pandemic. Front Psychiatry 2020;11:574676. 
31. COVID-19 national survey dashboard. Toronto: Centre for Addiction and Mental Health. Available: www.camh.ca/en/health-info/mental-health-and-covid-19/ covid-19-national-survey (accessed 2021 Jan. 22).

32. Segan CJ, Borland R, Greenwood KM. Do transtheoretical model measures predict the transition from preparation to action in smoking cessation? Psychol Health 2002;17:417-35.

33. Bold KW, Rasheed AS, McCarthy DE, et al. Rates and predictors of renewed quitting after relapse during a one-year follow-up among primary care patients. Ann Behav Med 2015;49:128-40.

34. Bhatti S, Commisso E, Rayner J. A rapid primary healthcare response to COVID-19: an equity-based and systems-thinking approach to care ensuring that no one is left behind. Healthc Q 2020;23:29-33.

35. Roberts ET, Mehrotra A. Assessment of disparities in digital access among medicare beneficiaries and implications for telemedicine. 7 AMA Intern Med 2020;180:1386-9.

36. Hart JT. The inverse care law. Lancet 1971;1:405-12.

37. Canada's tobacco strategy. Ottawa: Tobacco Control Directorate; 2018.

Competing interests: Peter Selby reports receiving grants and/or salary and/or research support from the National Research Council of Canada and the Canadian Institutes of Health Research (CIHR). No other competing interests were declared.

Affiliations: Nicotine Dependence Service (Minian, Veldhuizen, Tanzini, Duench, deRuiter, Barker, Zawertailo, Melamed, Selby), Centre for Addiction and Mental Health; Department of Family and Community Medicine (Minian), and Dalla Lana School of Public Health (Barker), and
Department of Pharmacology and Toxicology (Zawertailo), Faculty of Medicine, and Department of Family and Community Medicine (Melamed, Selby), University of Toronto, Toronto, Ont.

Contributors: Nadia Minian, Scott Veldhuizen and Peter Selby designed the study, Scott Veldhuizen analyzed the data. Nadia Minian, Scott Veldhuizen, Elise Tanzini, Stephanie Duench, Wayne deRuiter, Megan Barker wrote the original draft. All authors participated in the critical revision of the manuscript and approved the final report.

Funding: This work was supported by the Ontario Ministry of Health (grant number HLTC5047FL).

Content licence: This is an Open Access article distributed in accordance with the terms of the Creative Commons Attribution (CC BY-NC-ND 4.0) licence, which permits use, distribution and reproduction in any medium, provided that the original publication is properly cited, the use is noncommercial (i.e., research or educational use), and no modifications or adaptations are made. See: https://creativecommons.org/licenses/by-nc-nd/4.0/

Data sharing: Data are available from the corresponding author upon reasonable request.

Supplemental information: For reviewer comments and the original submission of this manuscript, please see www.cmajopen.ca/content/9/4/ E957/suppl/DC1. 